\title{
ACHIEVING UNIFORM CEMENT MANTLE OF OPTIMUM THICKNESS DURING ORTHOPAEDIC SURGERY
}

\author{
Rajshree Mootanah (1), Steeve Lamvohee (1), John Dowell (2)
}

1. Bioengineering Research Group, Anglia Ruskin University, UK. 2. Mid-Essex Hospitals Trust, Broomfield Hospital, UK.

\section{Introduction}

The stability of cemented hip replacements can be improved by achieving a uniform and optimum cement mantle thickness. However, in surgery, it is difficult to achieve this even thickness of cement mantle due the bottoming out of the cup. Some acetabular cups with $3 \mathrm{~mm}$ cement spacers exist on the market. However, the optimum cement thickness is not always $3 \mathrm{~mm}$ [Lamvohee et. al., 2006]. We investigated the use of cement spacers to produce uniform cement mantles of pre-defined thicknesses. Although bone cement is reasonably strong in compression, it is a relatively brittle material, making it susceptible to fracture as a result of tensile loads [Harper et al., 2000].

\section{Methods}

Bone cement samples were prepared with and without cement spacers as per British Standards Specifications - BS ISO 5833:2002 for 4-point bend test. The specimens were prepared in sizes of $75 \mathrm{~mm} \times 10 \mathrm{~mm} \times 3.3 \mathrm{~mm}$ and were conditioned at 23 degrees for 24 hours prior to testing. The specimens, with and without the pre-manufactured spacers, were loaded at a rate of $5 \mathrm{~mm}$ per minute, using a Hounsfield Mechanical testing machine, and deflections at the middle of the specimen were recorded at applied forces of $15 \mathrm{~N}$ and $50 \mathrm{~N}$, using linear variable displacement transducers. Different types of cement, including Smartset HV from Depuy and Simplex P from Stryker Howmedia Osteonics were used.

\section{Results}

This section presents the results of the four-point bend tests. The sample size of each group and for both types of bone cement is 16 . The results for the Smartset HV bone cement show that there was a reduction of $17.5 \%$ and $1.81 \%$ in the bending modulus and bending strength of the bone cement specimen respectively when comparing the results of the control group to those with one cement spacer placed centrally in the specimen. For the Simplex $\mathrm{P}$ bone cement, the respective reductions are $8.61 \%$ and $4.74 \%$. Moreover, using a two tailed test with a $95 \%$ confidence interval, the results show that the bending modulii and bending strengths for the control group and Group II are significantly different for both types of bone cements. However, when the cement spacers are placed away from the central location at $17.5 \mathrm{~mm}$ from each end of the specimen, the difference in the bending modulus and the bending strength of the bone cement for the control group and the group with two cement spacers is not significant. The reductions in the bending modulii and bending strength for the two types of bone cement are as follows: $2.89 \%$ and $1.81 \%$ for the Smartset $\mathrm{HV}$ bone cement and $1.61 \%$ and $2.17 \%$ for the Simplex $\mathrm{P}$ bone cement.

\begin{tabular}{ccccc}
\hline & \multicolumn{2}{c}{$\begin{array}{c}\text { Bending Modulus } \\
\text { (MPa) }\end{array}$} & \multicolumn{2}{c}{$\begin{array}{c}\text { Bending Strength } \\
\text { (MPa) }\end{array}$} \\
\cline { 2 - 5 } & $\begin{array}{c}\text { Smartse } \\
\text { t HV }\end{array}$ & $\begin{array}{c}\text { Simplex } \\
\text { P }\end{array}$ & $\begin{array}{c}\text { Smartse } \\
\text { t HV }\end{array}$ & $\begin{array}{c}\text { Simple } \\
\text { x P }\end{array}$ \\
\hline Gp I - & 2946 & 2855 & 66.3 & 73.8 \\
No & $(284)$ & $(338)$ & $(2.91)$ & $(2.60)$ \\
spacers & & & & \\
Gp II - & 2430 & 2609 & 58.4 & 70.3 \\
One & $(275)$ & $(336)$ & $(2.73)$ & $(2.97)$ \\
spacer & & & & \\
Gp III - & 2861 & 2809 & 65.1 & 72.2 \\
Two & $(391)$ & $(319)$ & $(3.03)$ & $(1.61)$ \\
spacers & & &
\end{tabular}

Table 1: Bending moduli and bending strengths of bone cements with and without spacers

\section{Discussion}

The results show that the inclusion of cement spacers in bone cement specimens, if positioned in regions of low stress concentrations, i.e. away from the superior portion of the acetabular, would not significantly affect the mechanical properties of the bone cement.

\section{References}

Lamvohee et al, proc. Computer Methods in Biomechanics and Biomedical Engineering, CD, 2006.

Harper et al, . Biomed Mater Res, 53(5): 605-616, 2000 . 